\title{
Urea for Chronic Hyponatremia
}

\author{
Helbert Rondon-Berrios \\ Renal-Electrolyte Division, University of Pittsburgh School of Medicine, Pittsburgh, PA, USA
}

\section{Keywords}

Hyponatremia · Inappropriate ADH syndrome · Urea

\begin{abstract}
Background: Hyponatremia is the most common electrolyte disorder encountered clinically. While acute and/or severe hyponatremia is commonly associated with significant symptoms, milder and more chronic forms of hyponatremia remain clinically inconspicuous. Recent evidence suggests that even milder forms of hyponatremia are associated with increased morbidity and mortality. Despite this, currently available treatments for chronic hyponatremia lack data on efficacy and/or have important limitations related to patient nonadherence, adverse side effects, and/or significant costs. Consequently, there is a clear need for investigation of alternative treatments for this common condition. Summary: Small case series conducted in Europe since the early 1980s suggest that urea, an oral osmotic diuretic that increases urinary water excretion, is safe and effective for the treatment of chronic hyponatremia. In 2016, a novel formulation of urea became available in the United States. Our group recently reported the first and only study describing the efficacy and safety of this American formulation of oral urea among hospitalized patients with hyponatremia. Key Messages: Oral urea appears to be an effective, safe, and welltolerated therapeutic strategy in the management of chronic hyponatremia.

(c) 2019 S. Karger AG, Basel
\end{abstract}

\section{KARGER}

(c) 2019 S. Karger AG, Basel

E-Mail karger@karger.com

www.karger.com/bpu

\section{Introduction}

Hyponatremia, defined as a plasma sodium $(\mathrm{PNa})$ concentration $<135 \mathrm{mmol} / \mathrm{L}$, is the most common electrolyte disorder encountered clinically. Hyponatremia is categorized as mild (i.e., PNa 130-134 mmol/L), moderate (i.e., $\mathrm{PNa} 120-129 \mathrm{mmol} / \mathrm{L}$ ), or severe (i.e., $\mathrm{PNa}<120$ $\mathrm{mmol} / \mathrm{L}$ ) and as acute (i.e., duration $<48 \mathrm{~h}$ ), or chronic (i.e., duration $\geq 48 \mathrm{~h}$ ). The small proportion of patients with this disorder who present with severe and/or acute hyponatremia frequently have overt neurological symptoms and require hospitalization and urgent treatment. Much more commonly, patients with this condition have chronic nonsevere hyponatremia that typically does not require hospitalization or urgent therapy. While such patients are seemingly asymptomatic, a growing body of evidence demonstrates that even mild chronic hyponatremia is associated with subtle neurocognitive deficits, gait and postural disturbances, development of osteoporosis, heightened risk for falls and fractures, and increased mortality [1]. As a result, there has been substantial interest in identifying treatments that can be used for the longterm management of patients with chronic hyponatremia that are safe, well-tolerated, and that mitigate the morbidity and mortality associated with this condition.

The most common etiology of chronic hyponatremia is the syndrome of inappropriate antidiuretic hormone secretion (SIADH) and interventions currently used to treat this condition are based on our understanding of its

Helbert Rondon-Berrio

Renal-Electrolyte Division

University of Pittsburgh School of Medicine

3550 Terrace Street, A915 Scaife Hall, Pittsburgh, PA 1561 (USA)

E-Mail rondonberriosh@upmc.edu 
pathophysiology. However, some of these treatments, including loop diuretics, oral sodium chloride tablets, and fluid restriction (FR), lack evidence of efficacy from clinical trials, and in the case of FR, pose significant challenges to long-term patient compliance. Other therapies such as vasopressin antagonists (i.e., vaptans) have been shown to improve $\mathrm{PNa}$ in clinical trials [2], yet their widespread use is limited by the notable risk for serious side effects, including liver injury, risk of overly rapid correction of $\mathrm{PNa}$, as well as very high costs. Consequently, at present, there are no treatment interventions available that have been shown in clinical trials to be efficacious, safe, easy for patients to adhere to, and affordable for long-term use.

Small case series conducted in Europe [3-7] have investigated the efficacy of increasing urinary solute excretion through the administration of oral urea and found this agent to be safe and effective for the treatment of hyponatremia. Moreover, oral urea has not been available for clinical use in the United States until recently when Ure- $\mathrm{Na}^{\mathrm{TM}}$, a novel commercial formulation was introduced. An intravenous urea formulation (Ureaphil) was available in the early 1960s for the treatment of elevated intracranial and intraocular pressure (given the osmotic properties of urea), but its use faded with the introduction of mannitol. Ureaphil was eventually discontinued in 2006. This review describes the pharmacology of urea, the evidence for its efficacy in hyponatremia, its adverse events, indications, contraindications, and practical recommendations for use in the management of chronic SIADH.

\section{Pharmacology of Oral Urea}

\section{Pharmacokinetics}

Over $90 \%$ of oral urea is absorbed in the upper gastrointestinal tract with $<4 \%$ reaching the colon where it is metabolized into ammonium by bacterial ureases. Urea distributes in total body water. In general, urea behaves as an ineffective osmole as it crosses cell membranes rapidly penetrating muscle tissue and reaching steady-state concentrations within $1 \mathrm{~h}$. However, urea's permeability across the blood brain barrier is much less and can take up to $10 \mathrm{~h}$ to penetrate brain tissue therefore urea here is considered a partially effective osmole [8]. The latter explains why urea was used as an osmotic agent for elevated intracranial pressure and intraocular pressure in the past. The half-life of oral urea is approximately $2 \mathrm{~h}$. A dose of oral urea is excreted in the urine within $12 \mathrm{~h}$ [9].

Urea for Hyponatremia

\section{Renal Handling of Urea}

Urea is freely filtered by the glomerulus. Fifty percent of filtered urea is passively reabsorbed in the proximal tubule. Urea is stored in the medulla where it makes up to $50 \%$ of solutes in the inner medulla. Some urea is secreted into the thin limbs of the loop of Henle (i.e., urea recycling) so the amount of urea at the beginning of the thick ascending limb reaches $110 \%$ of the filtered urea. Urea transporter UT-A2 has been identified as the urea transporter in the thin descending limb. The renal tubule is relatively impermeable to urea from the thick ascending limb of the loop of Henle to the outer medullary collecting duct (OMCD). Nevertheless, only about $50 \%$ of filtered urea remains in the lumen at the end of the OMCD. In the presence of vasopressin, about $20 \%$ of filtered urea is absorbed through UT-A1 urea transporters in the apical membrane the inner medullary collecting duct cells. Urea then exits these cells via UT-A3 urea transporters in the basolateral membrane. The net result is that only $30 \%$ of filtered urea is excreted in the urine (Fig. 1).

\section{Mechanism of Action of Urea in Hyponatremia}

Urea, with a molar mass of $60 \mathrm{~g} / \mathrm{mol}$, works as an effective osmole (i.e., osmotic diuretic) in nephron segments with high water permeability and low urea permeability, namely, the connecting tubule, cortical collecting duct, and OMCD. The effects of urea on free water excretion can be better explained by the dependence of free water excretion on solute excretion [10] (Table 1). Furthermore, the pathophysiology of hyponatremia in SIADH not only involves dilution from water accumulation but also a component of sodium loss [11]. Urea in SIADH has been shown to decrease natriuresis and creates a state of positive sodium balance which also contributes to the improvement of $\mathrm{PNa}$ [12].

\section{Efficacy of Urea in Hyponatremia}

Preliminary evidence of the efficacy of oral urea derives from small case series reported in Europe since the early 1980s (Table 2). Decaux and Genette [5] studied 7 patients with chronic hyponatremia and found that treatment with urea over a period of up to 9 months resulted in an increase in mean PNa from 116 to $136 \mathrm{mmol} / \mathrm{L}$ and was not associated with any major side effects. Another study by Decaux et al. [4] of 50 patients with mild to moderate hyponatremia (PNa 120-134 mmol/L) found that 2 days of treatment with urea increased $\mathrm{PNa}$ by $7 \pm 4$ 
Fig. 1. Renal handling of urea. Urea is freely filtered by the glomerulus. About half of filtered urea is reabsorbed in the proximal tubule. Urea is secreted into the lumen of the thin limbs (urea recycling) increasing urea concentration at the beginning of the thick ascending limb. From there on, urea permeability is reduced until reaching the CCD but greatly increases in the presence of vasopressin in the inner medullary collecting duct. Green dotted area represents the nephron segments with high water permeability and low urea permeability where urea exerts its osmotic effects. DVR, descending vasa recta; AVR, ascending vasa recta; UT-B, urea transporter UT-B; UTA2, urea transporter UT-A2; UT-A1/A3, urea transporters UT-A1 and UT-A3; CNT, connecting tubule; CCD, cortical collecting duct; OMCD, outer medullary collecting duct.

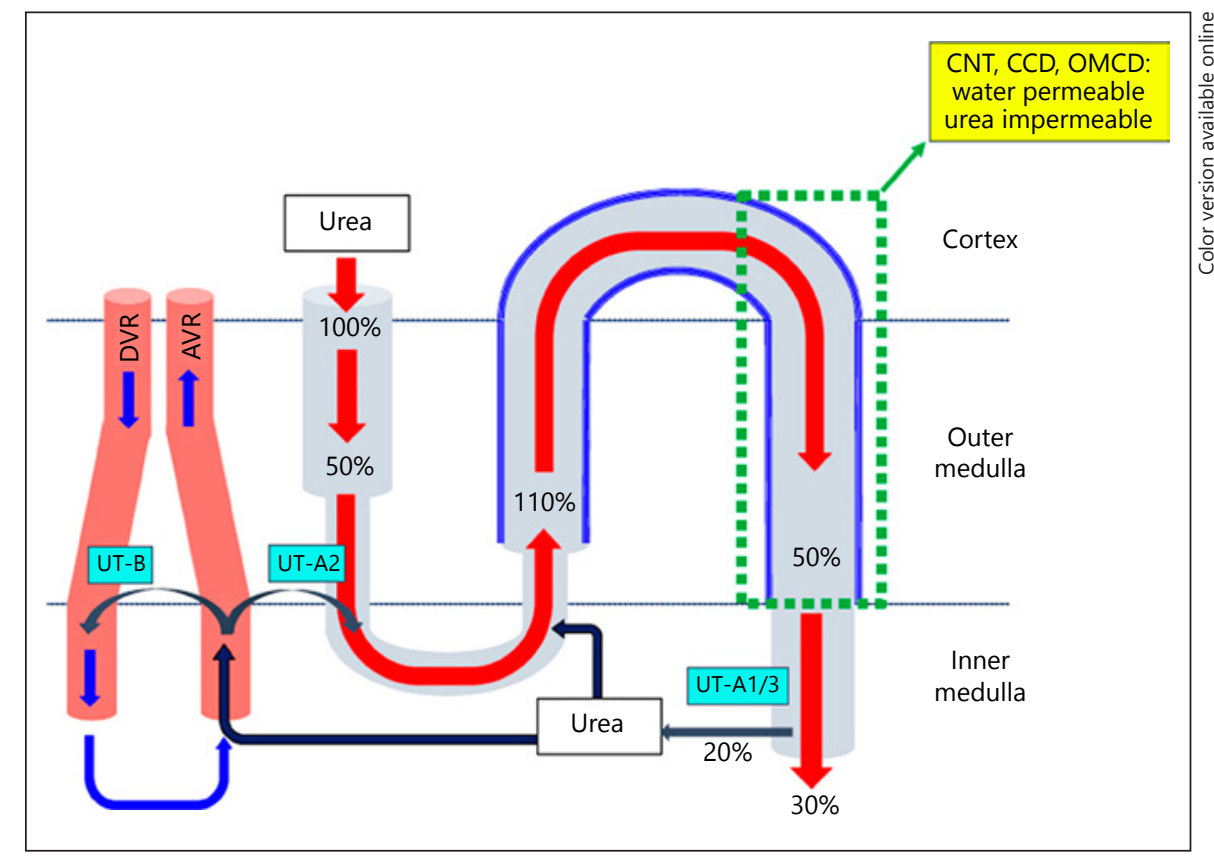

Table 1. Water balance under different settings

\begin{tabular}{|c|c|c|c|c|c|}
\hline Setting & $\begin{array}{l}\text { Solute intake, } \\
\text { mOsm/day }\end{array}$ & $\begin{array}{l}\text { Water intake, } \\
\text { L/day }\end{array}$ & $\begin{array}{l}\text { Urine osmolarity, } \\
\mathrm{mOsm} / \mathrm{L}\end{array}$ & $\begin{array}{l}\text { Urine volume, } \\
\text { L/day }\end{array}$ & $\begin{array}{l}\text { Water balance, } \\
\text { L/day }\end{array}$ \\
\hline Normal & 700 & 2 & $\begin{array}{l}=700 / 2 \\
=350\end{array}$ & 2 & 0 \\
\hline SIADH & 700 & 2 & 500 & $\begin{array}{l}=700 / 500 \\
=1.4\end{array}$ & +0.6 \\
\hline $\begin{array}{l}\text { SIADH }+\mathrm{NaCl} \\
6 \text { g/day }\end{array}$ & $\begin{array}{l}=700+205 \\
=905\end{array}$ & 2 & 500 & $\begin{array}{l}=905 / 500 \\
=1.8\end{array}$ & +0.2 \\
\hline $\begin{array}{l}\text { SIADH + Urea } \\
30 \text { g/day }\end{array}$ & $\begin{array}{l}=700+500 \\
=1,200\end{array}$ & 2 & 500 & $\begin{array}{l}=1,200 / 500 \\
=2.4\end{array}$ & -0.4 \\
\hline
\end{tabular}

(1) If a normal person, on solute and water balance, has a daily intake of $700 \mathrm{mOsm}$ of solute and $2 \mathrm{~L}$ of water, then the UOsm will be a reflection of the kidneys' ability to excrete solute and water to maintain homeostasis. UOsm is the ratio between the daily mass of solutes in the urine (\#Osm) and the daily urine volume (V), therefore $\mathrm{UOsm}=\# \mathrm{Osm} / \mathrm{V}$ or $700 / 2=350 \mathrm{mOsm} / \mathrm{L}$. Alternatively, $\mathrm{V}=\# \mathrm{Osm} / \mathrm{UOsm}$ or $700 / 350=2 \mathrm{~L}$. If the patient ingests $2 \mathrm{~L}$ of water daily (assuming no insensible losses) then the net daily water balance is $2-2=0$; (2) patients with the SIADH have a "fixed" UOsm. In the example on the table, we have a patient with fixed UOsm of 500 $\mathrm{mOsm} / \mathrm{L}$ with identical solute and water intake as in $(1)$, then $\mathrm{V}=\# \mathrm{Osm} / \mathrm{UOsm}$ or 700/500 $=1.4 \mathrm{~L}$. The net daily water balance is $2-1.4=+0.6 \mathrm{~L}$ and hyponatremia occurs; (3) If the same patient with SIADH with same "fixed" UOsm of $500 \mathrm{mOsm} / \mathrm{L}$ and same daily solute and water intake is treated with $\mathrm{NaCl}$ tablets $6 \mathrm{~g} /$ day $(205 \mathrm{mOsm} /$ day) then $\mathrm{V}=(700+205) / 500=1.8 \mathrm{~L}$. The net daily water balance is $2-1.8=+0.2 \mathrm{~L}$. (4) Finally, if the patient in (3) is treated instead with urea $30 \mathrm{~g} /$ day $(500 \mathrm{mOsm} /$ day $)$ then $\mathrm{V}=(700+500) / 500=2.4 \mathrm{~L}$. The net daily water balance is $2-2.4=-0.4 \mathrm{~L}$ and hyponatremia improves.

UOsm, urine osmolality; SIADH, syndrome of inappropriate antidiuretic hormone secretion. 
Table 2. Efficacy of urea in SIADH

\begin{tabular}{|c|c|c|c|c|c|c|c|}
\hline $\begin{array}{l}\text { Decaux and Genette } \\
{[5], 1981}\end{array}$ & $\begin{array}{l}\text { Observational } \\
\text { prospective }\end{array}$ & No & 7 & Outpatient & $115 \pm 6$ & $136 \pm 3.5$ & 270 \\
\hline $\begin{array}{l}\text { Decaux et al. } \\
{[4], 2010}\end{array}$ & $\begin{array}{l}\text { Observational } \\
\text { retrospective }\end{array}$ & No & $\begin{array}{l}\text { (I) } 50 \\
\text { (II) } 35\end{array}$ & $\mathrm{ICU}$ & $\begin{array}{l}\text { (I) } 128 \pm 4 \\
\text { (II) } 111 \pm 3\end{array}$ & $\begin{array}{l}\text { (I) } 135 \pm 4 \\
\text { (II) } 122 \pm 4\end{array}$ & $\begin{array}{l}\text { (I) } 2 \\
\text { (II) } 1\end{array}$ \\
\hline $\begin{array}{l}\text { Pierrakos et al. } \\
{[6], 2012}\end{array}$ & $\begin{array}{l}\text { Observational } \\
\text { prospective }\end{array}$ & No & 42 & ICU & $127 \pm 2$ & $\begin{array}{l}\text { Change at } 24 \mathrm{~h}= \\
+3(\mathrm{IQR} 1-6)\end{array}$ & 5 \\
\hline $\begin{array}{l}\text { Soupart et al. } \\
{[7], 2012}\end{array}$ & Quasiexperimental & Yes & 13 & Outpatient & $126 \pm 5$ & $135 \pm 3$ & 365 \\
\hline $\begin{array}{l}\text { Nervo et al. } \\
\text { [15], } 2019\end{array}$ & $\begin{array}{l}\text { Observational } \\
\text { retrospective }\end{array}$ & No & 36 & Outpatient & $123 \pm 4$ & $\begin{array}{l}>135 \text { at } 60 \text { days in } \\
91.7 \%\end{array}$ & 60 \\
\hline
\end{tabular}

$\mathrm{PNa}$, plasma sodium concentration; ICU, intensive care unit; IQR, interquartile range; SIADH, syndrome of inappropriate antidiuretic hormone secretion.

$\mathrm{mmol} / \mathrm{L}$. Collectively, these and other small studies demonstrated that urea increases $\mathrm{PNa}$. However, these studies were retrospective, lacked a control group, included small numbers of patients, used a formulation of urea that is not available in the United States, and did not examine whether the effect of urea on raising $\mathrm{PNa}$ translates into a reduction in morbidity and/or mortality.

In 2016, Ure- $\mathrm{Na}^{\mathrm{TM}}$, a novel formulation of oral urea became available in the United States. The US Food and Drug Administration considers urea as a medical food, and therefore, does not require a medical prescription for its use. The University of Pittsburgh Medical Center incorporated Ure- $\mathrm{Na}^{\mathrm{TM}}$ into their inpatient formulary in July 2016. Our group recently published the first and only study on the efficacy of this agent for the treatment of hyponatremia in the United States [13]. We identified patients hospitalized at University of Pittsburgh Medical Center with $\mathrm{PNa}<135 \mathrm{mmol} / \mathrm{L}$ who received urea, including a subgroup with SIADH who received urea as the sole drug therapy for hyponatremia ("urea-only"). We compared change in $\mathrm{PNa}$ in these "urea only" patients to a matched group of patients treated for SIADH but who did not receive urea. Overall, 58 patients received urea (7.5-90 g/day) over a median of 4.5 days and demonstrated an increase in $\mathrm{PNa}$ from 124 to 131 $\mathrm{mmol} / \mathrm{L}(p<0.001)$. Among 12 "urea-only" treated patients, $\mathrm{PNa}$ increased from 125 to $131 \mathrm{mmol} / \mathrm{L}(p=$ $0.001)$ with a greater proportion of these patients achieving normal $\mathrm{PNa}$ (33 vs. $8 \%, p=0.08$ ). While our study was retrospective and limited to hospitalized patients, the findings support the potential efficacy of this agent. Two recent studies have also confirmed the efficacy of urea $[14,15]$ one of them exclusively performed in cancer patients [15].

\section{Comparative Studies}

There is a single study reported in the literature comparing urea to other therapies for hyponatremia. Soupart et al. [7] studied the efficacy, safety, and tolerability of urea compared to vasopressin antagonists in 13 patients with chronic SIADH. Patients were treated with vaptans (satavaptan and tolvaptan) for 1 year. PNa increased from $125 \pm 3$ to $135 \pm 3 \mathrm{mEq} / \mathrm{L}$ by the end of the year. Vaptans were then discontinued, and patients were allowed to become hyponatremic again. After an 8-day washout period, oral urea was introduced and maintained for 1 year. 
PNa normalized in all patients (mean $\mathrm{PNa} 135 \pm 2 \mathrm{mEq} / \mathrm{L}$ ). The patients tolerated urea well with no significant side effects.

\section{Adverse Events Associated with Urea}

Decaux's group that has the most experience with the use of oral urea report rates of distaste of up to $15 \%$, but this does not affect long-term compliance with urea [16]. In a most recent study performed in cancer patients, who notably have a high prevalence of dysgeusia, only 5 patients out of 36 (14\%) discontinued urea due to distaste [15]. Another recent study from Australia observed that out of 69 patients, almost 23\% experienced side effects, mainly distaste, and none of them were severe. However, the distaste described in these studies occurred with a different formulation of urea [14]. Distaste is much improved with the sweet citrus flavor of the American formulation of urea. In our study, only 1 patient (1.7\%) discontinued urea due to distaste, and no side effects were observed [13]. Other reported side effects associated with the use of urea include nausea, vomiting, diarrhea, and headaches [9].

Overly rapid correction of $\mathrm{PNa}$ with the use of urea has been reported in 2 studies. Decaux and Andres [4] describe a PNa correction $>12 \mathrm{mEq} / \mathrm{L}$ in 12 out of $35(34.2 \%)$ patients with hyponatremia from SIADH treated with urea. However, it is difficult to establish causality as 10 out those 12 patients received thiazide diuretics and volume expansion with intravenous fluids. Pierrakos et al. [6] described overly rapid correction of hyponatremia in 4 out of 42 (9.5\%) patients treated with urea. In our study, no patients experienced overly rapid correction of $\mathrm{PNa}$ [13]. Nevertheless, even when urea is associated with some small risk of overly rapid correction of hyponatremia, there have been no reports of osmotic demyelination syndrome (ODS). Moreover, animal data suggest that urea maybe protective against ODS. Soupart et al. [17] studied rats that were induced severe azotemia, mild azotemia, or no azotemia and then underwent overly rapid correction of hyponatremia. Rats with severe azotemia had a significantly better survival and developed lesser degrees of demyelination upon brain analysis. Gankam Kengne et al. [18] studied hyponatremic rats whose $\mathrm{PNa}$ was overcorrected using urea, lixivaptan, or hypertonic saline. All animals developed a similar degree of PNa correction. Survival in the animals that received urea was significantly better than in the other 2 groups. Fewer animals that received urea developed ODS, and the few that did, had less pronounced neurologic manifestations compared to animals who received lixivaptan or hypertonic saline. These findings perhaps explain why the incidence of ODS in hemodialysis patients remains relatively low $[19,20]$. The mechanism by which urea protects ODS is unclear. It was initially thought that urea allows for the rapid reaccumulation of osmolytes during rapid correction of hyponatremia [21]. However, a subsequent study did not confirm these findings [22].

\section{Indications and Contraindications}

Urea's main indication is the treatment of hyponatremia due to SIADH. Urea may also be used in the hyponatremia of heart failure $[23,24]$. There have also been reports of the successful use of urea in the hyponatremia of cirrhosis $[25,26]$. In the latter scenario, there is a theoretical risk of hepatic encephalopathy as unabsorbed urea is metabolized into ammonium in the colon [27]. Urea has also been used to treat the nephrogenic syndrome of antidiuresis, an activating mutation of the vasopressin 2 receptor where vaptans are not effective [28].

\section{Dosing}

Oral urea is administered at a dose of $0.25-0.5 \mathrm{~g} / \mathrm{kg} /$ day with usual doses of 15, 30, and $60 \mathrm{~g} /$ day. In general, the higher the urine osmolality (a surrogate for negative electrolyte free-water clearance), the higher the urea dose needed to correct hyponatremia. Lockett et al. [14] observed in a recent study that no patients who were given a urea dose $<30 \mathrm{~g} /$ day normalized their PNa by $72 \mathrm{~h}$.

\section{Therapeutic Approach to SIADH with Urea}

The traditional first-line therapy for SIADH is FR. However, as many as $60-70 \%$ of patients with SIADH will not respond to FR alone [29]. Predictors of nonresponsiveness to FR in SIADH include a urine-to-plasma electrolyte ratio ([Urine $\mathrm{Na}+$ Urine $\mathrm{K}] / \mathrm{PNa})>1$ or a urine osmolality $>400-500 \mathrm{mOsm} / \mathrm{kg}$ [29-31]. Patients who are unlikely to respond to FR alone can be treated with oral urea in association with modest FR (i.e., 1-1.5 L/ day). We recommend an approach that considers the likelihood of FR responsiveness based on the above parameters (Fig. 2). 
Fig. 2. Management of chronic hyponatremia due to SIADH with urea. SIADH, syndrome of inappropriate antidiuretic hormone secretion; UNa, urine sodium; UK, urine potassium; $\mathrm{PNa}$, plasma sodium; UOsm, urine osmolality; FR, fluid restriction.

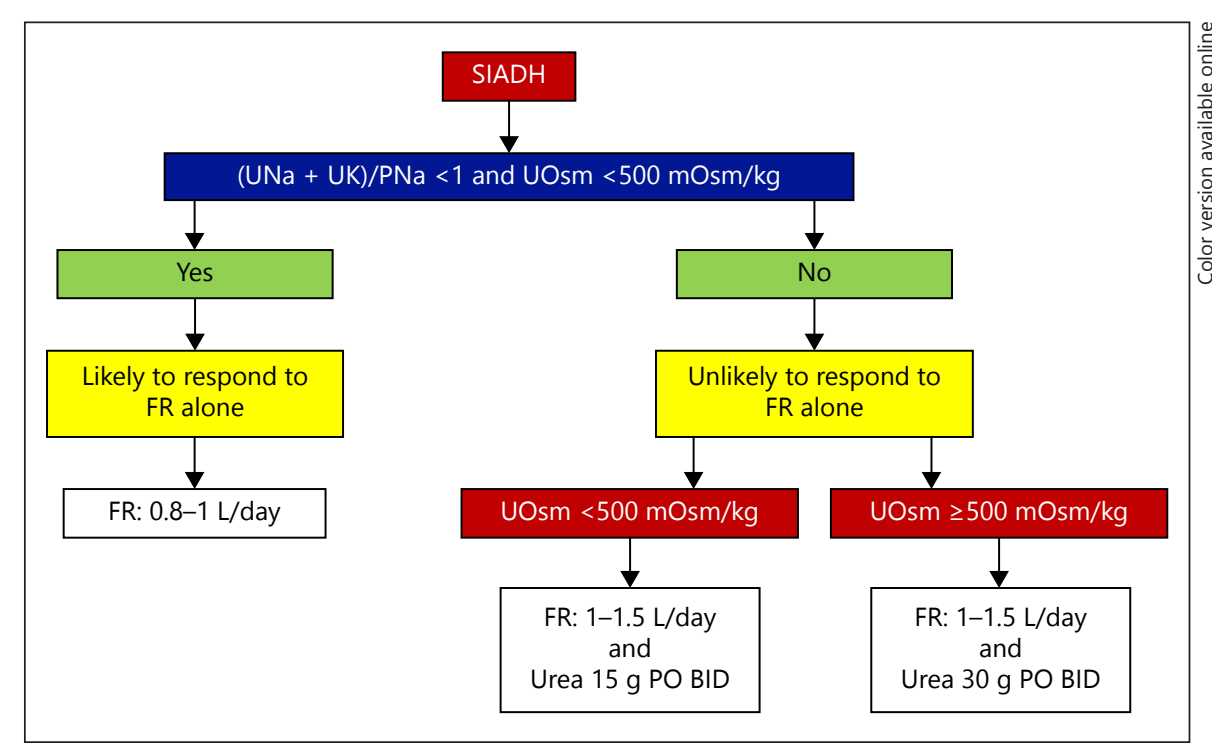

Disclosure Statement

Author has no conflict of interest to declare.

\section{Funding Sources}

This research received no specific grant from any funding agency in the public, commercial, or not-for-profit sectors.

\section{References}

1 Rondon-Berrios H, Berl T. Mild Chronic Hyponatremia in the Ambulatory Setting: significance and Management. Clin J Am Soc Nephrol. 2015 Dec;10(12):2268-78.

2 Schrier RW, Gross P, Gheorghiade M, Berl T, Verbalis JG, Czerwiec FS, et al.; SALT Investigators. Tolvaptan, a selective oral vasopressin V2-receptor antagonist, for hyponatremia. N Engl J Med. 2006 Nov;355(20):2099112.

3 Coussement J, Danguy C, Zouaoui-Boudjeltia K, Defrance P, Bankir L, Biston P, et al. Treatment of the syndrome of inappropriate secretion of antidiuretic hormone with urea in critically ill patients. Am J Nephrol. 2012;35(3): 265-70.

4 Decaux G, Andres C, Gankam Kengne F, Soupart A. Treatment of euvolemic hyponatremia in the intensive care unit by urea. Crit Care. 2010;14(5):R184.

5 Decaux G, Genette F. Urea for long-term treatment of syndrome of inappropriate secretion of antidiuretic hormone. Br Med J (Clin Res Ed). 1981 Oct;283(6299):1081-3.
6 Pierrakos C, Taccone FS, Decaux G, Vincent $\mathrm{JL}$, Brimioulle S. Urea for treatment of acute SIADH in patients with subarachnoid hemorrhage: a single-center experience. Ann Intensive Care. 2012 May;2(1):13.

7 Soupart A, Coffernils M, Couturier B, Gankam-Kengne F, Decaux G. Efficacy and tolerance of urea compared with vaptans for long-term treatment of patients with SIADH. Clin J Am Soc Nephrol. 2012 May;7(5):742-7.

8 Kleeman CR, Davson H, Levin E. Urea transport in the central nervous system. Am J Physiol. 1962 Oct;203(4):739-47.

9 Sterns RH, Silver SM, Hix JK. Urea for hyponatremia? Kidney Int. 2015 Feb;87(2):26870.

10 Berl T. Impact of solute intake on urine flow and water excretion. J Am Soc Nephrol. 2008 Jun;19(6):1076-8.

11 Verbalis JG. Whole-body volume regulation and escape from antidiuresis. Am J Med. 2006 Jul;119(7 Suppl 1):S21-9.

12 Verbalis JG, Baldwin EF, Neish PN, Robinson AG. Effect of protein intake and urea on so- dium excretion during inappropriate antidiuresis in rats. Metabolism. 1988 Jan;37(1): 46-54.

13 Rondon-Berrios H, Tandukar S, Mor MK, Ray EC, Bender FH, Kleyman TR, et al. Urea for the Treatment of Hyponatremia. Clin J Am Soc Nephrol. 2018 Nov;13(11): 1627-32.

14 Lockett J, Berkman KE, Dimeski G, Russell AW, Inder WJ. Urea treatment in fluid restriction-refractory hyponatraemia. Clin Endocrinol (Oxf). 2019 Apr;90(4):630-6.

15 Nervo A, D’Angelo V, Rosso D, Castellana E, Cattel F, Arvat E, et al. Urea in cancer patients with chronic SIAD-induced hyponatremia: old drug, new evidence. Clin Endocrinol (Oxf). 2019 Jun;90(6):842-8.

16 Decaux G, Gankam Kengne F, Couturier B, Vandergheynst F, Musch W, Soupart A. Actual Therapeutic Indication of an Old Drug: Urea for Treatment of Severely Symptomatic and Mild Chronic Hyponatremia Related to SIADH. J Clin Med. 2014 Sep;3(3): 1043-9. 
17 Soupart A, Penninckx R, Stenuit A, Decaux G. Azotemia $(48 \mathrm{~h})$ decreases the risk of brain damage in rats after correction of chronic hyponatremia. Brain Res. 2000 Jan;852(1):16772.

18 Gankam Kengne F, Couturier BS, Soupart A, Decaux G. Urea minimizes brain complications following rapid correction of chronic hyponatremia compared with vasopressin antagonist or hypertonic saline. Kidney Int. 2015 Feb;87(2):323-31.

19 Dhrolia MF, Akhtar SF, Ahmed E, Naqvi A, Rizvi A. Azotemia protects the brain from osmotic demyelination on rapid correction of hyponatremia. Saudi J Kidney Dis Transpl. 2014 May;25(3):558-66.

20 Oo TN, Smith CL, Swan SK. Does uremia protect against the demyelination associated with correction of hyponatremia during hemodialysis? A case report and literature review. Semin Dial. 2003 Jan-Feb;16(1):6871.

21 Soupart A, Silver S, Schroöeder B, Sterns R, Decaux G. Rapid (24-hour) reaccumulation of brain organic osmolytes (particularly myoinositol) in azotemic rats after correction of chronic hyponatremia. J Am Soc Nephrol. 2002 Jun;13(6):1433-41.

22 Soupart A, Schroëder B, Decaux G. Treatment of hyponatraemia by urea decreases risks of brain complications in rats. Brain osmolyte contents analysis. Nephrol Dial Transplant. 2007 Jul;22(7):1856-63.

23 Berghmans T, Meert A, Sculier JP. Correction of hyponatremia by urea in a patient with heart failure. Acta Clin Belg. 2005 Sep-Oct; 60(5):244-6.

24 Cauchie P, Vincken W, Decaux G. Urea treatment for water retention in hyponatremic congestive heart failure. Int J Cardiol. 1987 Oct;17(1):102-4.

25 Decaux G, Mols P, Cauchi P, Delwiche F. Use of urea for treatment of water retention in hyponatraemic cirrhosis with ascites resistant to diuretics. Br Med J (Clin Res Ed). 1985 Jun; 290(6484):1782-3.

26 Decaux G, Mols P, Cauchie P, Flamion B, Delwiche $F$. Treatment of hyponatremic cirrhosis with ascites resistant to diuretics by urea. Nephron. 1986;44(4):337-43.

27 Phillips GB, Schwartz R, Gabuzda GJ Jr, Davidson CS. The syndrome of impending he- patic coma in patients with cirrhosis of the liver given certain nitrogenous substances. N Engl J Med. 1952 Aug;247(7):239-46.

28 Vandergheynst F, Brachet C, Heinrichs C, Decaux G. Long-term treatment of hyponatremic patients with nephrogenic syndrome of inappropriate antidiuresis: personal experience and review of published case reports. Nephron Clin Pract. 2012;120(3):c168-72.

29 Decaux G, Gankam Kengne F, Couturier B, Musch W, Soupart A, Vandergheynst F. Mild water restriction with or without urea for the longterm treatment of syndrome of inappropriate antidiuretic hormone secretion (SI$\mathrm{ADH})$ : can urine osmolality help the choice? Eur J Intern Med. 2018 Feb;48:89-93.

30 Verbalis JG, Goldsmith SR, Greenberg A, Korzelius C, Schrier RW, Sterns RH, et al. Diagnosis, evaluation, and treatment of hyponatremia: expert panel recommendations. Am J Med. 2013 Oct;126(10 Suppl 1):S1-42.

31 Winzeler B, Lengsfeld S, Nigro N, Suter-Widmer I, Schütz P, Arici B, et al. Predictors of nonresponse to fluid restriction in hyponatraemia due to the syndrome of inappropriate antidiuresis. J Intern Med. 2016 Dec;280(6):609-17. 